\title{
Phylogeny of Helicobacter Isolates from Bird and Swine Feces and Description of Helicobacter pametensis sp. nov.
}

\author{
FLOYD E. DEWHIRST, ${ }^{1 *}$ CHARLES SEYMOUR, ${ }^{2}$ GAYLE J. FRASER, ${ }^{1}$ BRUCE J. PASTER, ${ }^{1}$ \\ AND JAMES G. FOX ${ }^{3}$ \\ Department of Molecular Genetics, Forsyth Dental Center, Boston, Massachusetts $02115^{1}$; Department of Microbiology, \\ Boston University School of Medicine, Boston, Massachusetts $02118^{2}$; and Division of Comparative Medicine, \\ Massachusetts Institute of Technology, Cambridge, Massachusetts $02139^{3}$
}

\begin{abstract}
Previously, nine fecal isolates from wild birds and a domestic swine were identified as helicobacters by phenotypic characterization and reaction with a helicobacter genus-specific DNA probe. These isolates fell into three biotypes by analysis of phenotypic traits. To further characterize these isolates, full 16S rRNA sequences were determined for strains representing each biotype, and sequence comparison indicated that the strains represented three novel, phylogenetically defined Helicobacter species. Three 16S rRNA-based DNA probes were designed and used to identify the remaining strains. Probe reactivity divided the strains into the same three groups identified phenotypically. Six of the isolates represented a new species of the genus Helicobacter for which we propose the name Helicobacter pametensis sp. nov. The following phenotypic features distinguished $H$. pametensis from other Helicobacter and Campylobacter species: positive tests for oxidase, catalase, alkaline phosphatase, nitrate reduction, growth at $42^{\circ} \mathrm{C}$, and growth in the presence of $1 \%$ glycine; negative tests for urease, gamma glutamyl transpeptidase, indoxyl acetate hydrolysis, and hippurate hydrolysis; and susceptibility to nalidixic acid and cephalothin. $H$. pametensis cells were motile and possessed one subterminal sheathed flagellum at each end. The two additional Helicobacter species were similar to $H$. pametensis except that they were urease positive, hydrolyzed indoxyl acetate, and were resistant to cephalothin. Because these two additional species are phenotypically similar and are represented by only two isolates for one species and one isolate for the other, they are not formally named but are referred to as Helicobacter sp. "Bird-B" and Helicobacter sp. "Bird-C." These three new Helicobacter species can easily be confused with Campylobacter coli, Campylobacter lari, and Campylobacter jejuni if only a limited number of phenotypic traits are used for identification. Since it is now known that birds can harbor Helicobacter as well as Campylobacter species, methods which clearly distinguish these genera should be used to identify bird campylobacter-like isolates or bacterial strains traceable to bird fecal contamination. The zoonotic potential of these new Helicobacter species should be examined.
\end{abstract}

The genera Helicobacter, Wolinella, Campylobacter, and Arcobacter constitute the epsilon division of the Proteobacteria (42), also known as RNA superfamily VI (47). The genus Helicobacter is currently composed of 10 named species: Helicobacter pylori $(17,25), H$. mustelae $(14,17,32), H$. felis $(23$, $32), H$. muridarum $(24), H$. fennelliae $(12,46,47), H$. cinaedi $(12,46,47), H$. nemestrinae $(4,40), H$. acinonyx $(11), H$. canis $(7,43)$, and $H$. hepaticus $(13)$. Strains representing additional species have been identified by rRNA-DNA hybridization (47) and 16S rRNA sequence analysis $(11,43)$. These include "Flexispira rappini," $(2,6,38)$ and CLO-3 (12, 46, 47). Two uncultivable human gastric spiral organisms, "Gastrospirillum hominis" 1 and 2 , have been identified as helicobacters by $16 \mathrm{~S}$ rRNA analysis (41).

$H$. pylori, $H$. acinonyx, $H$. nemestrinae, $H$. mustelae, and $H$. felis colonize the gastric mucosae of their hosts. All except $H$. nemestrinae produce gastric diseases ranging from mild gastrititis or ulcers to gastric carcinoma $(4,11,14,15,25,26,29,32)$. $H$. cinaedi, $H$. fennelliae, $H$. canis, and $H$. muridarum colonize the intestinal tract and can produce gastroenteritis $(2,7,12$, 46). $H$. muridarum can colonize the stomachs as well as ceca of older rats (24). $H$. hepaticus colonizes the gastrointestinal tracts of mice and has the pathogenic potential to elicit a persistent hepatitis (13). Human infections with $H$. cinaedi and

${ }^{*}$ Corresponding author. Mailing address: Forsyth Dental Center, 140 Fenway, Boston, MA 02115. Phone: (617) 262-5200, ext. 298. Fax: (617) $262-4021$.
H. canis may be zoonotic, because the primary hosts are hamsters (16) and dogs $(7,43)$, respectively.

In this study, we describe nine Helicobacter isolates obtained primarily from wild birds (39). Six of these isolates fall within one species, for which we propose the name Helicobacter pametensis sp. nov. The remaining three isolates constitute two additional Helicobacter species, which are described but which will not be formally named until additional isolates are obtained and characterized.

\section{MATERIALS AND METHODS}

Bacterial strains and culture conditions. The initial isolations from feces and characterization of the Helicobacter strains examined in this report have been described previously (39). Helicobacters were cultured microaerophilically on Trypticase soy agar II with 5\% sheep blood (BBL Becton Dickinson Microbiology Systems) at $37^{\circ} \mathrm{C}$. Microaerophilic conditions were established by culture in Brewer jars evacuated to 25 in. $(63.50 \mathrm{~cm})$ of $\mathrm{Hg}$ and filled with $\mathrm{N}_{2}-\mathrm{H}_{2}-\mathrm{CO}_{2}(80: 10: 10$ [vol/ vol]) or by use of a campylobacter gas pack (BBL Becton Dickinson Microbiology Systems).

Biochemical characterization. Partial biochemical characterization of these nine strains was previously reported (31, 39). Alkaline phosphatase and naphthylamide aminopeptidases were determined with An-Ident panels (Analytab Products, Plainview, N.Y.). Cells grown on Trypticase soy agar II with $5 \%$ sheep blood were collected and suspended in distilled water (or the diluent required by the commercial tests) to a 
TABLE 1. Sources and accession numbers of strains studied

\begin{tabular}{|c|c|c|c|c|}
\hline Organism & Strain examined ${ }^{a}$ & Culture collection no. ${ }^{b}$ & GenBank no. ${ }^{c}$ & Reference $^{d}$ \\
\hline \multicolumn{5}{|l|}{ Isolates } \\
\hline Helicobacter pametensis & Seymour B $9^{\mathrm{T}}$ & CCUG $29255^{\mathrm{T}}$, ATCC $51478^{\mathrm{T}}$ & M88147 & \\
\hline Helicobacter pametensis & Seymour B7 & CCUG 29253 & M88145 & \\
\hline Helicobacter pametensis & Seymour B12 & CCUG 29257, ATCC 51479 & M88140 & \\
\hline Helicobacter pametensis & Seymour B13 & CCUG 29258 & M88141 & \\
\hline Helicobacter pametensis & Seymour B15 & CCUG 29259 & M88142 & \\
\hline Helicobacter pametensis & Seymour M17 & CCUG 29260 & M88155 & \\
\hline Helicobacter sp. Bird-B & Seymour B10 ${ }^{\mathrm{T}}$ & CCUG $29256^{\mathrm{T}}$, ATCC $51480^{\mathrm{T}}$ & M88139 & \\
\hline Helicobacter sp. Bird-B & Seymour B8 & CCUG 29254, ATCC 51481 & M88146 & \\
\hline Helicobacter sp. Bird-C & Seymour $\mathrm{B} 52^{\mathrm{T}}$ & CCUG $29561^{\mathrm{T}}$, ATCC $51482^{\mathrm{T}}$ & M88144 & \\
\hline \multicolumn{5}{|l|}{ Reference species } \\
\hline Arcobacter cryaerophilus & CCUG $17801^{\mathrm{T}}$ & ATCC $43158^{\mathrm{T}}$ & L14624 & 43 \\
\hline Arcobacter butzleri & CCUG 10373 & & L14626 & 43 \\
\hline Arcobacter skirrowii & CCUG $10374^{\mathrm{T}}$ & & L16625 & 43 \\
\hline Campylobacter coli & CCUG $11238^{\mathrm{T}}$ & ATCC $33559^{\mathrm{T}}$ & L04312 & 11 \\
\hline Campylobacter concisus & Tanner $484^{\mathrm{T}}$ & ATCC $33237^{T}$ & L04322 & 11 \\
\hline Campylobacter fetus subsp. fetus & ATCC $27374^{\mathrm{T}}$ & & M65012 & 48 \\
\hline Campylobacter lari & CCUG $23947^{\mathrm{T}}$ & ATCC $35221^{\mathbf{T}}$ & L04316 & 11 \\
\hline Campylobacter rectus & Tanner $371^{\mathrm{T}}$ & ATCC $33238^{\mathrm{T}}$ & L04317 & 11 \\
\hline "Flexispira rappini" & NADC $1893^{T}$ & ATCC $43966^{\mathbf{T}}$ & M88137 & 11 \\
\hline "Gastrospirillum hominis" 1 & Uncultivable & & L10079 & 41 \\
\hline "Gastrospirillum hominis" 2 & Uncultivable & & L10080 & 41 \\
\hline Helicobacter acinonyx & Eaton $90-119-3^{\mathrm{T}}$ & ATCC $51101^{\mathrm{T}}$, CCUG $29263^{\mathrm{T}}$ & M88148 & 11 \\
\hline Helicobacter canis & NCTC $12739^{\mathrm{T}}$ & & L13464 & 43 \\
\hline Helicobacter cinaedi & CCUG $18818^{\mathrm{T}}$ & ATCC $35683^{\mathrm{T}}$ & M88150 & 43 \\
\hline Helicobacter felis & Lee $\operatorname{CS}^{\mathbf{T}}$ & ATCC $49179^{T}$ & M37642 & 32 \\
\hline Helicobacter felis & Lee DS3 & Not deposited & M37643 & 32 \\
\hline Helicobacter fennelliae & CCUG $18820^{\mathrm{T}}$ & ATCC $35684^{\mathrm{T}}$ & M88154 & 43 \\
\hline Helicobacter mustelae & Fox R85-13-6 ${ }^{\mathrm{T}}$ & ATCC $43772^{\text {T }}$ & M35048 & 32 \\
\hline Helicobacter muridarum & Lee $S T 1^{\mathrm{T}}$ & CCUG $29262^{\mathrm{T}}$, ATCC $49282^{\mathrm{T}}$ & M80205 & 23 \\
\hline Helicobacter nemestrinae & ATCC $49396^{\mathrm{T}}$ & & X67854 & 40 \\
\hline Helicobacter pylori & ATCC $43504^{\mathrm{T}}$ & & M88157 & 11 \\
\hline Helicobacter sp. CLO 3 & CCUG 14564 & & M88151 & 43 \\
\hline Wolinella succinogenes & Tanner $602 \mathrm{~W}^{\mathrm{T}}$ & ATCC $29543^{\mathrm{T}}$ & M88159 & 11 \\
\hline
\end{tabular}

\footnotetext{
${ }^{a}$ Strains from which sequences were determined were obtained from the following individuals or culture collections: K. A. Eaton, Department of Veterinary Pathobiology, Ohio State University, Columbus; J. G. Fox, Division of Comparative Medicine, Massachusetts Institute of Technology, Cambridge; A. Lee, Department of Microbiology and Immunology, University of New South Wales, Sydney, Australia; C. Seymour, Department of Microbiology, Boston University School of Medicine, Boston, Mass.; A. Tanner, Department of Microbiology, Forsyth Dental Center, Boston, Mass.; ATCC, American Type Culture Collection, Rockville, Md.; CCUG, Culture Collection, University of Göteborg, Göteborg, Sweden; NADC, National Animal Disease Center, Ames, Iowa; and NCTC, National Collections of Type Cultures, London, United Kingdom.

${ }^{b}$ Alternate culture collection sources for sequenced strains.

c $16 \mathrm{~S}$ rRNA sequences for these strains are available for electronic retrieval from GenBank under the accession numbers given above. Through cross-distribution of databases, these sequences should also be available from the EMBL and DDBJ databases.

${ }^{d}$ Literature references to sequences not obtained in this paper.
}

density corresponding to that of a no. $5 \mathrm{McFarland}$ turbidity standard. Following addition of inoculating suspension to each microwell, the strips were incubated at $37^{\circ} \mathrm{C}$ for $4 \mathrm{~h}$. Aminopeptidase reactions were developed by addition of cinnamaldehyde reagent. Oxidase was determined with DrySlide oxi-

TABLE 2. DNA probes

\begin{tabular}{ccr}
\hline Target & $\begin{array}{c}\text { Location } \\
\text { (bases) }^{a}\end{array}$ & Sequence \\
\hline $\begin{array}{c}\text { All campy- } \\
\text { lobacters }\end{array}$ & $400-423$ & 5'-CGAAAAGTGTCATCCTCCACGCGG-3' $^{\prime}$ \\
$\begin{array}{c}\text { All helico- } \\
\text { bacters }\end{array}$ & $274-300$ & $5^{\prime}$-TCTCAGGCCGGATACCCGTCATAGCCT-3' \\
Strain B9 & $818-845$ & 5'-ACAAGCTCCACAACAACTAGCATTCATC-3' \\
Strain B10 & $623-651$ & 5'-GAGTAATAGTTTCAAATGCAGTTCTGTAG-3' $^{\prime}$ \\
Strain B52 & $1010-1033^{b}$ & 5'-GTAAACTAGACACTCCATATCTCT-3' \\
\hline
\end{tabular}

${ }^{a}$ Numbering relative to $E$. coli (5).

${ }^{b}$ Note that strain B52 has one extra base relative to $E$. coli in this region and is 25 rather than 24 bases long. dase slides (Difco). Catalase activity was determined by formation of bubbles upon addition of a loopful of cells to 100 $\mu l$ of $3 \%$ hydrogen peroxide. Gamma glutamyl transpeptidase was determined by adding $100 \mu \mathrm{l}$ of a no. $5 \mathrm{McF}$ arland density suspension of cells to a microtiter well containing $0.1 \mathrm{mg}$ of L-glutamic acid $\gamma$-(4-methoxy- $\beta$-naphthylamide) (Sigma). Cells were incubated for $4 \mathrm{~h}$ at $37^{\circ} \mathrm{C}$, and the reaction was developed by addition of 1 drop of cinnamaldehyde reagent (Innovative Diagnostics, Inc.). Urease activity was determined by using Christensen (8) urease test agar (Remel, Lenexa, Kans.) incubated at $37^{\circ} \mathrm{C}$ for $4 \mathrm{~h}$. Indoxyl acetate hydrolysis was determined by the impregnated disc method (18) with a 20 -min incubation at room temperature. Methods for testing antibiotic sensitivity, hippurate hydrolysis, $\mathrm{H}_{2} \mathrm{~S}$ production, and growth in the presence of $3.5 \% \mathrm{NaCl}$ and $1 \%$ glycine were described previously (39).

Electron microscopy. Cells grown on Trypticase soy agarblood plates were gently suspended in $10 \mathrm{mM}$ Tris buffer $(\mathrm{pH}$ 7.4) at a concentration of approximately $10^{8}$ cells per ml. Samples were negatively stained with $1 \%$ (wt/vol) phospho- 
TABLE 3. Differential characteristics of helicobacter isolates ${ }^{a}$

\begin{tabular}{|c|c|c|c|c|c|c|c|c|c|c|c|}
\hline \multirow[b]{2}{*}{ Biotype } & \multirow[b]{2}{*}{ Strain } & \multirow[b]{2}{*}{ Source } & \multirow{2}{*}{$\begin{array}{l}\text { Urease } \\
\text { activity }\end{array}$} & \multirow{2}{*}{$\begin{array}{l}\text { Indoxyl } \\
\text { acetate } \\
\text { hydrolysis }\end{array}$} & \multicolumn{2}{|c|}{ Susceptibility to: } & \multicolumn{5}{|c|}{ Reactivity with probe specific for: } \\
\hline & & & & & Cephalothin & $\begin{array}{l}\text { Nalidixic } \\
\text { acid }\end{array}$ & Campylobacter & Helicobacter & B9 & B10 & B52 \\
\hline A & B7 & Tern & - & - & $\mathrm{S}$ & $\mathbf{S}$ & - & + & + & - & - \\
\hline A & B9 & Tern & - & - & $\mathrm{S}$ & $\mathrm{S}$ & - & + & + & - & - \\
\hline A & B12 & Gull & - & - & $\mathrm{S}$ & $\mathrm{S}$ & - & + & + & - & - \\
\hline A & B13 & Gull & - & - & $\mathrm{S}$ & $\mathrm{S}$ & - & + & + & - & - \\
\hline A & B15 & Gull & - & - & $\mathrm{S}$ & $\mathrm{S}$ & - & + & + & - & - \\
\hline A & M17 & Pig & - & - & $\mathrm{S}$ & $\mathrm{S}$ & - & + & + & - & - \\
\hline B & B8 & Tern & + & + & $\mathbf{R}$ & $\mathrm{S}$ & - & + & - & + & - \\
\hline B & B10 & Tern & + & + & $\mathbf{R}$ & $\mathrm{S}$ & - & + & - & + & - \\
\hline $\mathrm{C}$ & B52 & House sparrow & + & + & $\mathrm{R}$ & MS & - & + & - & - & + \\
\hline
\end{tabular}

${ }^{a}-$, negative reaction; + , positive reaction; $\mathrm{R}$, resistant, no zone of inhibition; S, sensitive (zone of inhibition, $<20 \mathrm{~mm}$ ); MS, marked sensitivity (zone of inhibition, $>25 \mathrm{~mm}$ ) with $30-\mu \mathrm{g}$ antibiotic-impregnated discs.

tungstic acid ( $\mathrm{pH} 6.5$ ) for 20 to $30 \mathrm{~s}$. Specimens were examined with a JEOL model JEM-1200EX transmission electron microscope operating at $100 \mathrm{kV}$.

$\mathbf{G}+\mathbf{C}$ content of DNA. The $\mathrm{G}+\mathrm{C}$ contents of DNAs were determined by thermal denaturation analysis as described by Breznak and Canale-Parola (3) and calculated with the equation of De Ley (9). DNA isolated from Escherichia coli K-12 was used for control determinations.

16S rRNA sequencing. rRNA was isolated and partially purified by phenol extraction and ethanol and salt precipitations as previously described (30). rRNA was sequenced by using a modified Sanger dideoxy chain termination technique in which primers complementary to conserved regions were elongated with avian myeloblastosis virus reverse transcriptase (22). The details of our protocol, including special sequencing primers, have been previously described $(11,30)$.

16S rRNA data analysis. A program set for data entry, editing, sequence alignment, secondary structure comparison, similarity matrix generation, and dendrogram construction for 16S rRNA data was written in Microsoft QuickBASIC for use on IBM PC-AT and compatible computers (30). RNA sequences were entered and aligned as previously described (30). Our sequence database contains approximately 300 sequences determined in our laboratory and another 200 sequences

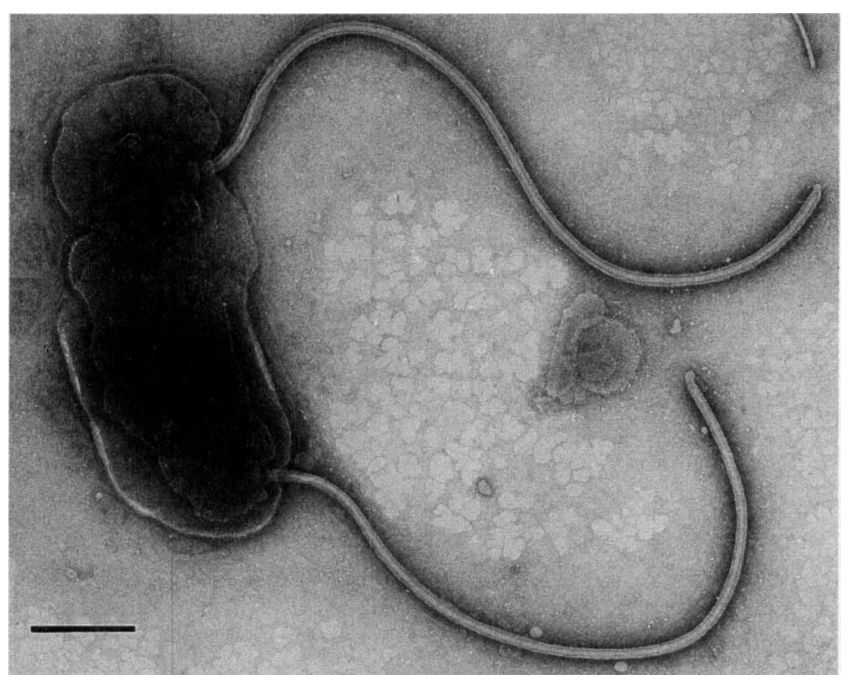

FIG. 1. Transmission electron micrograph of $H$. pametensis $\mathrm{B}^{\mathrm{T}}$. Note that flagella are sheathed. Bar, $0.3 \mu \mathrm{m}$. obtained from GenBank or the Ribosomal Database Project (27). Reference strains used in the $16 \mathrm{~S}$ rRNA analysis are given in Table 1. Similarity matrices were constructed from the aligned sequences by using only those sequence positions for which $90 \%$ of the strains had data. The similarity matrices were corrected for multiple base changes by the method of Jukes and Cantor (20). Phylogenetic trees were constructed by the neighbor-joining method of Saitou and Nei $(35,45)$.

DNA probe design, synthesis, and labeling. DNA probes were designed by locating 24- to 30-base regions of 16S rRNA sequence in which the target organism differed from the sequences of all related organisms as previously described (10). Oligonucleotides were synthesized on an ABI 392 DNA/RNA Synthesizer (Foster City, Calif.). The probes used in this study are given in Table 2. Validation of the all-helicobacter and all-campylobacter probes has been previously reported (15, 39).

DNA probe labeling. Probe oligonucleotides were end labeled with $\left.{ }^{32} \mathrm{P}\right] \mathrm{ATP}$ by using the $\mathrm{T} 4$ polynucleotide kinase method (36). The labeled oligonucleotide probes were purified by chromatography on a Sep-Pak $\mathrm{C}_{18}$ column (37).

Dot blot hybridization. Whole cells were harvested from agar plates and spotted onto Whatman 541 filter paper. Hybridization of probes to partially lysed fixed cells was performed as previously described (10). Bound radioactivity was localized and quantitated with a Betascope 603 (Betagen, Waltham, Mass.).

Nucleotide sequence accession number. The GenBank and culture collection accession numbers for the strains examined in this report are given in Table 1.

\section{RESULTS AND DISCUSSION}

The nine isolates were catalase, oxidase, alkaline phosphatase, and nitrate reduction positive. As previously reported, they grew at $42^{\circ} \mathrm{C}$ in the presence of $1 \%$ glycine but not in the presence of $3.5 \% \mathrm{NaCl}(39)$. They did not hydrolyze hippurate or show gamma glutamyl transpeptidase activity. The naphthylamine aminopeptidase tests were of little value for differentiating among Helicobacter and Campylobacter species. The isolates were positive for hydrolysis of the arginine betanaphthylamide but negative for hydrolysis of leucine, proline, pyroglutamate, tyrosine, phenylalanine, and glycine beta-naphthylamides. Alanine and histidine beta-naphthylamide tests were usually negative but sometimes weakly positive and thus were unreliable. The strains differed in their urease, indoxyl acetate hydrolysis, and antibiotic sensitivity tests, and, on the basis of these tests, the strains were divided into three biotypes 
彳 N-NNH

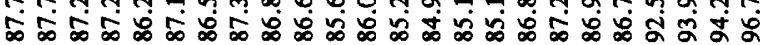
గุ̣

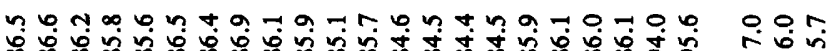
$0 \infty n-7$ T 安

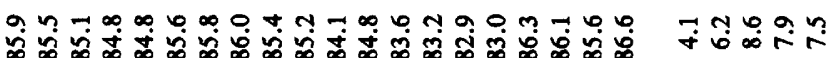

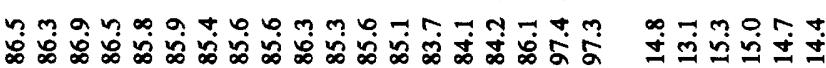

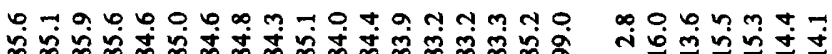

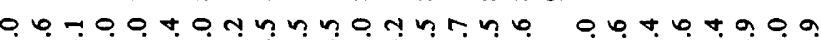
ஆ భ a t t t

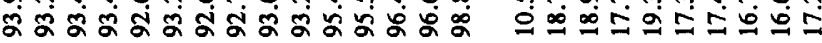

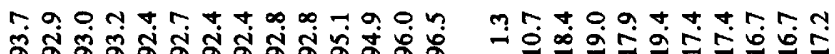

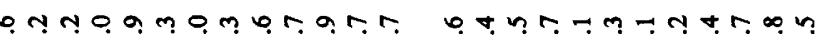
สু

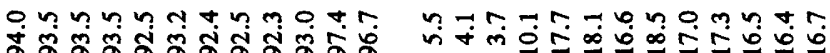

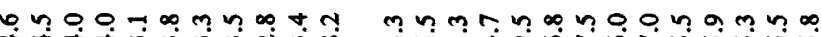

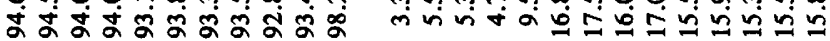

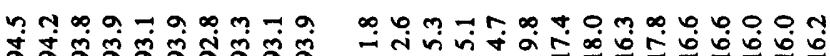
ఈ ๘

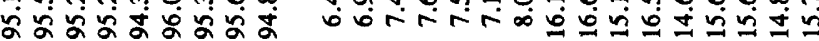

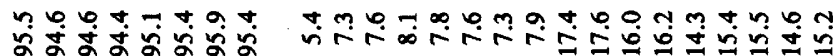
ทด

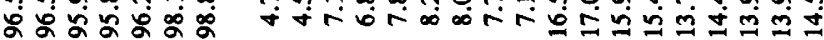

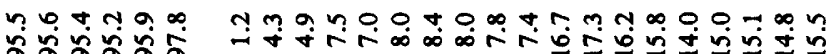

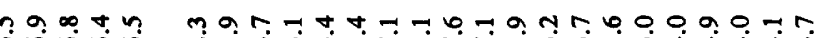

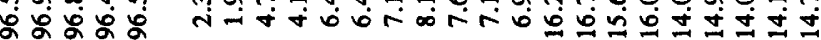

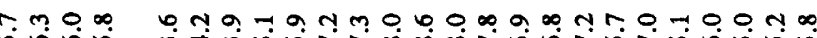

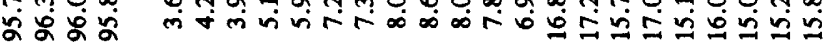

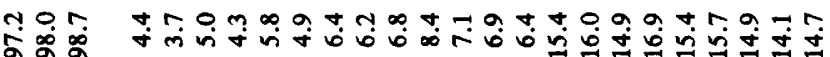
am $m-N \infty N 00 n N \infty N m a-m 0+0 a m+0+$

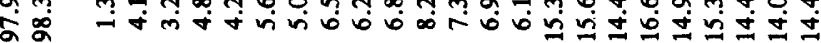

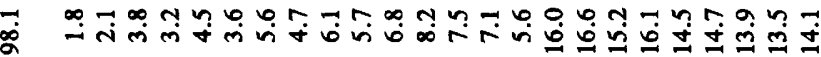

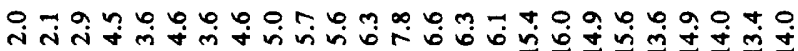

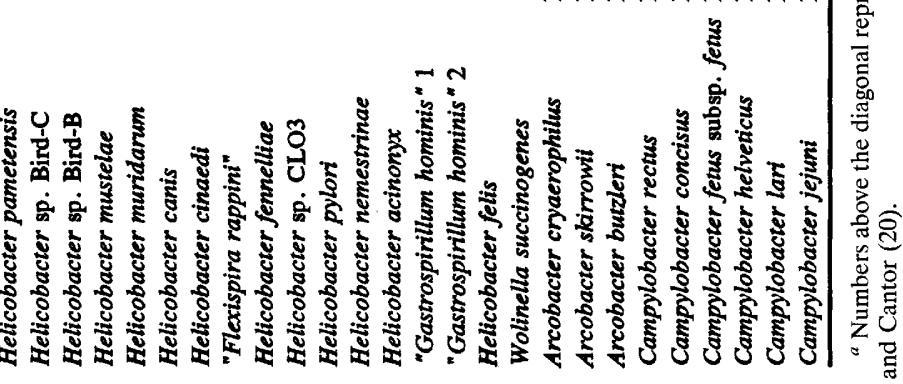




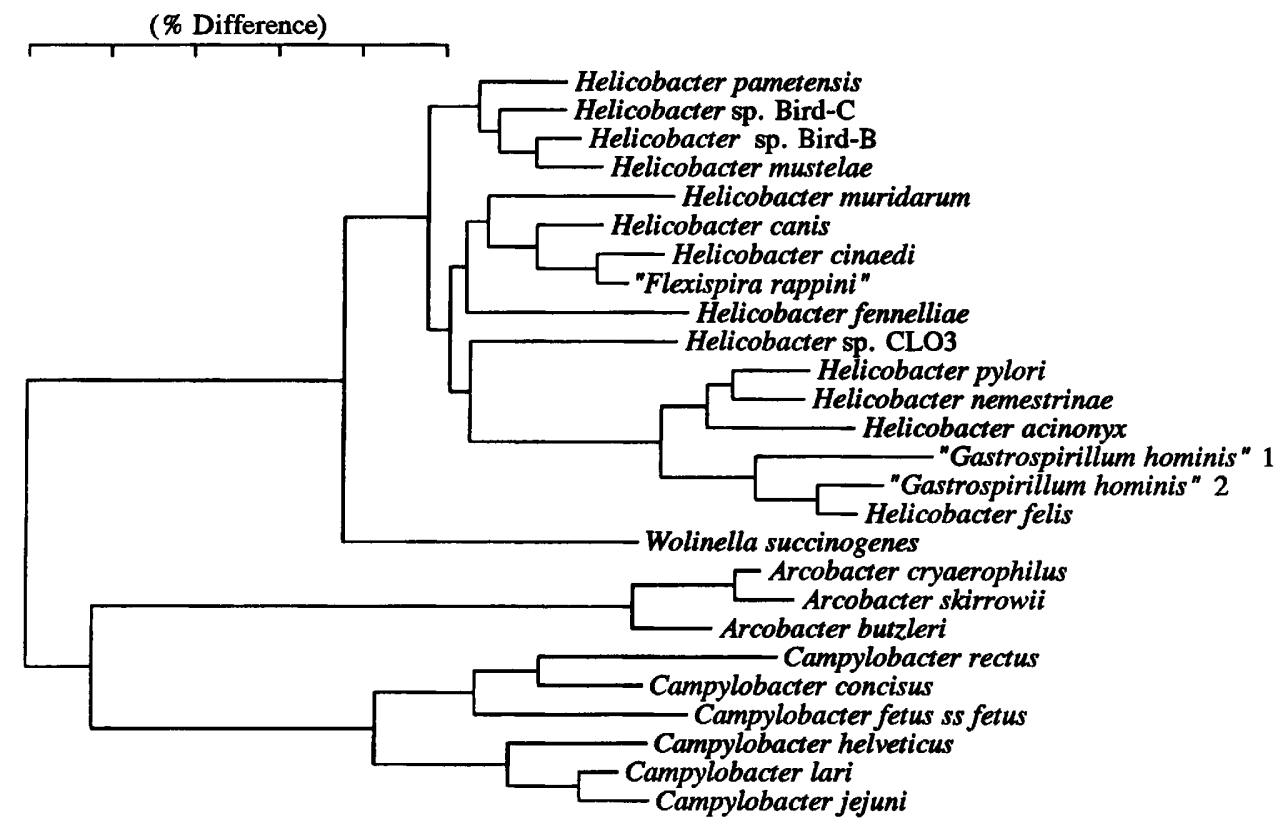

FIG. 2. Phylogenetic tree for strains representing 26 species of Helicobacter, Arcobacter, Campylobacter, and related bacteria based on 16S rRNA sequence similarity data. The scale bar represents a $5 \%$ difference in nucleotide sequences, as determined by measuring the lengths of horizontal lines connecting any two species.

(Table 3). The sole difference between biotypes $\mathrm{B}$ and $\mathrm{C}$ is that the biotype $B$ strains had moderate sensitivity to nalidixic acid (zone of inhibition, $<20 \mathrm{~mm}$ ) and strain B52 showed marked sensitivity to nalidixic acid (zone of inhibition, $>25 \mathrm{~mm}$ ). The separation of biotypes $B$ and $C$ was subsequently validated by the molecular sequencing and DNA probe data described below.

Phase microscopy of cells representing each of the three biotypes yielded similar results. Cells were curved or, occasionally, short spiral rods. In older cultures (greater than 3 days), coccoid forms predominated. Rapidly motile cells were seen in young cultures ( 1 to 2 days). Growth often formed as thin films that swarmed over Trypticase soy agar-blood plates. Electron micrographic examination of cells representative of each biotype revealed curved rods $0.4 \mu \mathrm{m}$ in diameter by $1.5 \mu \mathrm{m}$ in length. An electron micrograph of strain B9 is shown in Fig. 1. Usually a single sheathed flagellum was inserted subterminally at each end of the cell. However, about $10 \%$ of cells possessed a third flagellum inserted subterminally adjacent to one of the other two flagella. Other strains representing biotypes A, B, and $\mathrm{C}$ appeared identical by electron microscopy, although a third flagellum was not observed in biotypes $\mathrm{B}$ and $\mathrm{C}$.

Using eight primers, $95 \%$ of the $16 \mathrm{~S}$ rRNA sequence (approximately 1,450 bases) was determined for one representative strain of each of the three biotypes: B9, B10, and B52 for biotypes $\mathrm{A}, \mathrm{B}$, and $\mathrm{C}$, respectively. The sequences for each of the strains were unique. Comparison of the sequences with others in our database indicated that each of the three strains represented new species in the genus Helicobacter. DNA probes were designed and synthesized on the basis of comparison of these sequences with all other Helicobacter sequences in our database (Table 2). The remaining six isolates were screened for hybridization to these DNA probes (Table 3). Probe reactivity corresponded exactly to the previously determined biotypes. Subsequently, full $16 \mathrm{~S}$ rRNA sequences were obtained for all isolates. The sequences for the six strains of biotype A differed from one another by three or fewer base changes. The sequences for the two strains of biotype B were identical.

A similarity matrix for a total of 26 Helicobacter, Campylobacter, Arcobacter, and Wolinella species is shown in Table 4. A dendrogram showing the phylogenetic relationships for these species is shown in Fig. 2. The three new species of fecal helicobacters are most closely related to $H$. mustelae.

Bootstrapping with the program MEGA (21a) was performed with 300 resamplings and pairwise elimination of incomplete data. The clade composed of $H$. mustelae and Helicobacter $\mathrm{sp}$. Bird-B was present in $98 \%$ of the resamplings. The clade composed of Helicobacter sp. Bird-C and the two previous species was present in $74 \%$ of the resamplings. The clade composed of $H$. pametensis and the three previous species was present in $98 \%$ of the resamplings. In separate analyses including the five $H$. pametensis strains and the two Helicobacter sp. Bird-B strains, the strains fell with their respective species in $100 \%$ of 100 resamplings. Since Helicobacter sp. Bird-C is represented by only one strain, nothing can be inferred about its reproducibility at the species level. Bootstrap analysis examines the robustness of sequence data for reproducing a given tree by resampling with replacement but does not indicate the reliability of a given phylogenetic tree. With the above caveat, the bootstrap analysis reported strongly supports $(100 \%)$ the existence of $H$. pametensis and Helicobacter sp. Bird-B as taxa separate from other described species.

On the basis of the sequence and phenotypic data, we propose the name Helicobacter pametensis sp. nov. for the six isolates of biotype A. A formal description of this species is given below. Because of the limited number of strains and limited differential characteristics for biotypes B and C, we will not formally name these species. We will refer to them as Helicobacter sp. Bird-B and Helicobacter sp. Bird-C in accordance with their biotypes.

Differentiation of these new Helicobacter species from each other and from Campylobacter species such as C. coli, C. jejuni, 


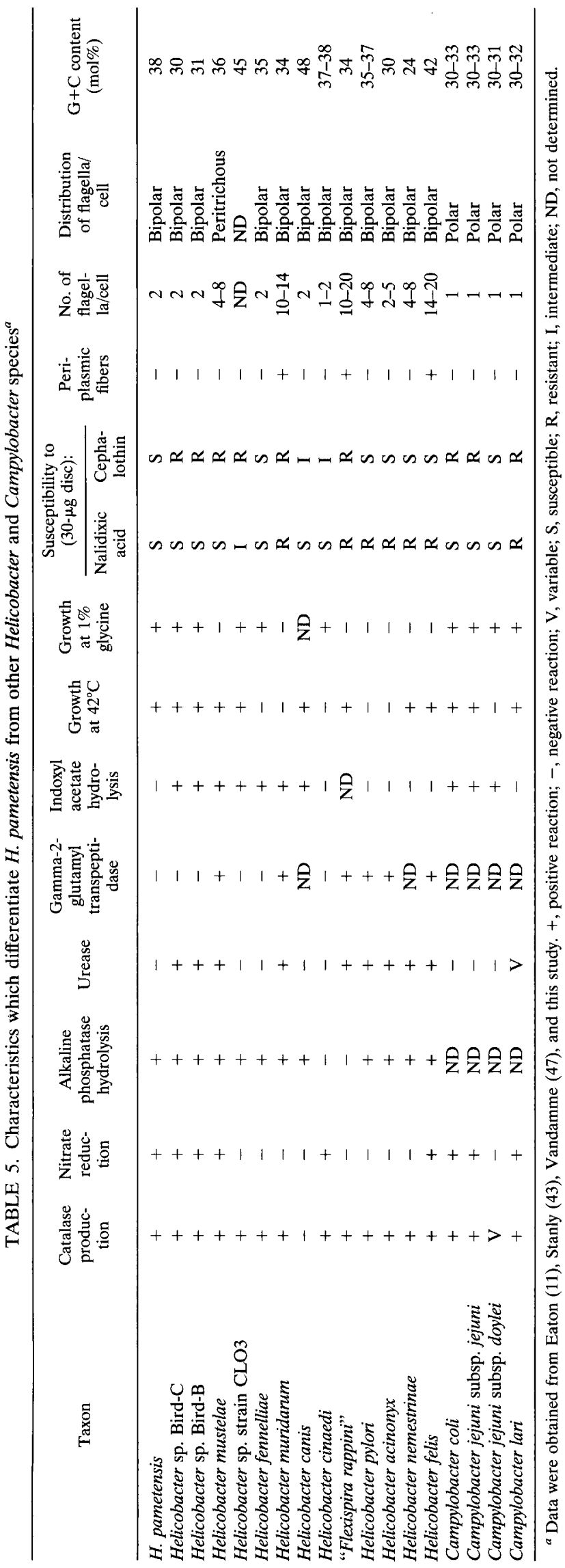

and $C$. lari is difficult by using phenotypic traits (Table 5). $H$. pametensis, Helicobacter sp. Bird-B, Helicobacter sp. Bird-C, $C$. coli, C. jejuni subsp. jejuni, and C. lari are all oxidase, catalase, and nitrate reduction positive; are $\mathrm{H}_{2} \mathrm{~S}$ production negative; and grow at $42^{\circ} \mathrm{C}$ and in the presence of $1 \%$ glycine but do not grow at $25^{\circ} \mathrm{C}$ or in the presence of $3.5 \% \mathrm{NaCl}$. Resistance to nalidixic acid differentiates $C$. lari from the other five species. Sensitivity to cephalothin distinguishes $H$. pametensis from the remaining four species. $C$. lari and $H$. pametensis are also distinguished from the other four species by a negative test for indoxyl acetate hydrolysis. Thus, even with 11 phenotypic tests, Helicobacter sp. Bird-B, Helicobacter sp. Bird-C, C. coli, and $C$. jejuni subsp. jejuni would still be indistinguishable. Hippurate hydrolysis, urease, and alkaline phosphatase tests differentiate these species. However, it is quite possible that bird Helicobacter species have been misidentified as Campylobacter species in previous studies relying on a limited number of phenotypic traits. In our previous study, we obtained 22 thermotolerant campylobacter-like isolates from birds (39). Thirteen isolates were identified as C. jejuni, C. coli, or C. lari on the basis of phenotypic criteria. Nine isolates differed from these typical Campylobacter species in one or more biochemical tests. Eight of the atypical isolates reacted with an allhelicobacter DNA probe. One atypical isolate was a mixed culture, containing C. jejuni and Helicobacter sp. Bird-C. It was only through reactivity with both the all-campylobacter probe and all-helicobacter probe that we realized the culture was mixed and eventually separated it into pure cultures of each species. With the limited number of reliable phenotypic traits known for these organisms and the number of Campylobacter, Arcobacter, and Helicobacter species approaching 50 (including species not formally named but identified by $16 \mathrm{~S}$ rRNA sequence analysis), it is becoming difficult to reliably differentiate species by traditional biochemical characterization. Molecular tools have the potential to distinguish each of these species, but almost no DNA probes have been validated against the most recently described species. Because of the limited number of changes in the 16S rRNA between closely related species, we find that it is not always possible to identify a Helicobacter species by using a single probe based on $16 \mathrm{~S}$ rRNA sequences. It may be prudent for laboratories to confirm presumptively identified isolates by a second method such as sodium dodecyl sulfate-polyacrylamide gel electrophoresis protein profiles.

While the zoonotic potential of the three new Helicobacter species is unknown, isolates of $H$. pametensis were recovered from two different species of wild birds and a domestic pig, suggesting that the species has a broad host range. Other intestinal helicobacters such as $H$. canis and $H$. cinaedi may on occasion cause human gastroenteritis by zoonotic transmission $(7,16,28)$. Zoonotic transmission of Campylobacter jejuni infection by birds is well known, with domestic poultry being the major source of human infection (44). Recent reports implicate wild birds, principally magpies (Pica pica) and jackdaws (Corvus monedula), as a source of $C$. jejuni-contaminated milk. Birds contaminated milk in bottles placed on porches by pecking through the bottle caps $(19,34)$. This novel method of zoonotic transmission of $C$. jejuni emphasizes that wild birds are an extensive reservoir of $C$. jejuni (21). During an outbreak of waterborne campylobacteriosis in military personnel, identical serotypes of $C$. jejuni were cultured from affected humans and from a common teal (Anas crecca) that may have contaminated the water supply (1). It has been noted that the concentration of campylobacters in surface water is highly dependent upon water temperature and the presence of waterfowl (33). It seems highly probable that humans are exposed 
to these newly identified fecal helicobacters as well as the more well-known campylobacters. Further studies are required to ascertain whether humans are colonized with these enteric helicobacters and, importantly, to ascertain if these bacteria can cause diarrheal disease in humans or other mammals.

Description of $\boldsymbol{H}$. pametensis sp. nov. Helicobacter pametensis (pa.me.ten'sis. N.L. of the Pamet River, Truro, Mass.). The description is based in part on our previous data (39). Cells are curved gram-negative rods, approximately $0.4 \mu \mathrm{m}$ in diameter by $1.5 \mu \mathrm{m}$ in length, with rounded ends. Cells are motile and possess one sheathed flagellum inserted subterminally at each end. Occasionally cells possess a third flagellum adjacent to one of the other flagella. No endospores are produced. Growth in a microaerobic environment at $37^{\circ} \mathrm{C}$ and $42^{\circ} \mathrm{C}$. There is weak growth under anaerobic conditions, and there is no growth in air at $37^{\circ} \mathrm{C}$. Oxidase, catalase, alkaline phosphatase, and arginine beta-naphthylamide aminopeptidase activities are produced. Proline, pyroglutamate, tyrosine, alanine, phenylalanine, and glycine beta-naphthylamide aminopeptidases and gamma glutamyl transpeptidase activities are not detected. Hippurate, urea, and indoxyl acetate are not hydrolyzed. $\mathrm{H}_{2} \mathrm{~S}$ is not produced on a triple sugar iron slant. Lysine and ornithine decarboxylase activity are not detected. Nitrate is reduced to nitrite. Growth occurs in the presence of $1 \%$ glycine but not in the presence of $3.5 \% \mathrm{NaCl}$. H. pametensis is sensitive to nalidixic acid but resistant to cephalothin when $30-\mu \mathrm{g}$ antibiotic-impregnated discs are used.

$H$. pametensis has been isolated from tern, gull, and swine feces. Six strains have been isolated (B7, B9, B12, B13, B15, and M17). Strains $B 9^{\mathrm{T}}$ and $\mathrm{B} 12$ are available from the American Type Culture Collection as ATCC 51478 and ATCC 51479 , respectively. All strains are available from the Culture Collection of the University of Göteborg, Göteborg, Sweden (CCUG 29253, 29255, and 29257 to 29260 , respectively). The type strain, B9 ${ }^{\mathrm{T}}$ (ATCC $51478^{\mathrm{T}}$, CCUG $29255^{\mathrm{T}}$ ), has a G+C content of $38 \mathrm{~mol} \%$. The essentially complete 16S rRNA sequence of the type strain of $H$. pametensis, B9, is available from the GenBank, EMBL, and DDBJ databases under accession number M88147.

\section{ACKNOWLEDGMENTS}

We thank Thomas O. MacAdoo, Virginia Polytechnic Institute and State University, for assistance in naming the organism. We thank Enevold Falsen, curator of the Culture Collection, University of Göteborg, for providing Campylobacter and Helicobacter strains.

This work was supported by grants DE-08303 and DE-10374 from the National Institutes of Dental Research, grant CA-26731 from the National Cancer Institute, and grants RR-01046 and RR-07036 from the National Center for Research Resources.

\section{REFERENCES}

1. Aho, M., M. Kurki, H. Rautelin, and T. U. Kosunen. 1989. Waterborne outbreak of Campylobacter enteritis after outdoors infantry drill in Utti, Finland. Epidemiol. Infect. 103:133-141.

2. Archer, J. R., S. Romero, A. E. Ritchie, M. E. Hamacher, B. M. Steiner, J. H. Bryner, and R. F. Schell. 1988. Characterization of an unclassified microaerophilic bacterium associated with gastroenteritis. J. Clin. Microbiol. 26:101-105.

3. Breznak, J. A., and E. Canale-Parola. 1975. Morphology and physiology of Spirochaeta aurantia strains isolated from aquatic habitats. Arch. Microbiol. 105:1-12.

4. Bronsdon, M. A., C. S. Goodwin, L. I. Sly, T. Chilvers, and F. D. Schoenknecht. 1991. Helicobacter nemestrinae sp. nov., a spiral bacterium found in the stomach of a pigtailed macaque (Macaca nemestrina). Int. J. Syst. Bacteriol. 41:148-153.

5. Brosius, J., M. L. Palmer, P. J. Kennedy, and H. F. Noller. 1978. Complete nucleotide sequence of a 16S ribosomal RNA gene from Escherichia coli. Proc. Natl. Acad. Sci. USA 75:4801-4805.
6. Bryner, J. H., A. E. Ritchie, L. Pollet, C. A. Kirkbride, and J. E. Collins. 1987. Experimental infection and abortion of pregnant guinea pigs with a unique spirillum-like bacterium isolated from aborted ovine fetuses. Am. J. Vet. Res. 48:91-95.

7. Burnens, A. P., J. Stanley, U. B. Schaad, and J. Nicolet. 1993. Novel Campylobacter-like organism resembling Helicobacter fennelliae isolated from a boy with gastroenteritis and from dogs. $\mathrm{J}$. Clin. Microbiol. 31:1916-1917.

8. Christensen, W. B. 1946. Urea decomposition as a means of differentiating Proteus and paracolon cultures from each other and from Salmonella and Shigella types. J. Bacteriol. 52:461-466.

9. De Ley, J. 1970. Reexamination of the association between melting point, buoyant density, and chemical base composition of deoxyribonucleic acid. J. Bacteriol. 101:738-754.

10. Dewhirst, F. E., C.-K. C. Chen, B. J. Paster, and J. J. Zambon. 1993. Phylogeny of species in the family Neisseriaceae isolated from human dental plaque and description of Kingella orale sp. nov. Int. J. Syst. Bacteriol. 43:490-499.

11. Eaton, K. A., F. E. Dewhirst, M. J. Radin, J. G. Fox, B. J. Paster, S. Krakowka, and D. R. Morgan. 1993. Helicobacter acinonyx sp. nov., isolated from cheetahs with gastritis. Int. J. Syst. Bacteriol. 43: $99-106$.

12. Fennell, C. L., P. A. Totten, T. C. Quinn, D. L. Patton, K. K. Holmes, and W. E. Stamm. 1984. Characterization of Campylobacter-like organisms isolated from homosexual men. J. Infect. Dis. 149:58-66.

13. Fox, J. G., F. E. Dewhirst, J. G. Tully, B. J. Paster, L. Yan, N. S. Taylor, M. J. Collins, P. L. Gorelick, and J. M. Ward. 1994. Helicobacter hepaticus sp. nov., a microaerophilic bacterium isolated from livers and intestinal mucosal scrapings from mice. J. Clin. Microbiol. 32:1238-1245.

14. Fox, J. G., B. M. Edrise, E. B. Cabot, C. Beacage, J. C. Murphy, and K. Prostak. 1986. Campylobacter-like organisms isolated from the gastric mucosa of ferrets. Am. J. Vet. Res. 47:236-239.

15. Fox, J. G., B. J. Paster, F. E. Dewhirst, N. S. Taylor, L.-L. Yan, P. J. Macuch, and L. M. Chmura. 1992. Helicobacter mustelae isolation from feces of ferrets: evidence to support fecal-oral transmission of a gastric helicobacter. Infect. Immun. 60:606-611.

16. Gebhart, C. J., C. L. Fennell, M. P. Murtaugh, and W. E. Stamm. 1989. Campylobacter cinaedi is normal intestinal flora in hamsters. J. Clin. Microbiol. 27:1692-1694.

17. Goodwin, C. S., J. A. Armstrong, T. Chilvers, M. Peters, M. D. Collins, L. Sly, W. McConnell, and W. E. S. Harper. 1989. Transfer of Campylobacter pylori and Campylobacter mustelae to Helicobacter gen. nov. as Helicobacter pylori comb. nov. and Helicobacter mustelae comb. nov., respectively. Int. J. Syst. Bacteriol. 39:397-405.

18. Hodge, D. S., A. Borczyk, and L.-L. Wat. 1990. Evaluation of the indoxyl acetate hydrolysis test for the differentiation of campylobacters. J. Clin. Microbiol. 28:1482-1483.

19. Hudson, S. J., N. F. Lightfoot, J. C. Coulson, K. Russell, P. R. Sisson, and A. O. Sobo. 1991. Jackdaws and magpies as vectors of milkborne human Campylobacter infection. Epidemiol. Infect. 107:363-372.

20. Jukes, T. H., and C. R. Cantor. 1969. Evolution of protein molecules, p. 21-132. In H. N. Munro (ed.), Mammalian protein metabolism, vol. 3. Academic Press, Inc., New York.

21. Kapperud, G., and O. Rosef. 1983. Avian wildlife reservoir of Campylobacter fetus subsp. jejuni, Yersinia spp., and Salmonella spp. in Norway. Appl. Environ. Microbiol. 45:375-380.

21a.Kumar, S., K. Tamura, and M. Nei. 1993. MEGA: molecular evolutionary genetics analysis, version 1.0. The Pennsylvania State University, University Park.

22. Lane, D. J., B. Pace, G. J. Olsen, D. A. Stahl, M. L. Sogin, and N. R. Pace. 1985. Rapid determination of 16 S ribosomal RNA sequences for phylogenetic analyses. Proc. Natl. Acad. Sci. USA 82:6955-6959.

23. Lee, A., S. L. Hazell, J. O'Rourke, and S. Kouprach. 1988. Isolation of a spiral-shaped bacterium from the cat stomach. Infect. Immun. 56:2843-2850.

24. Lee, A., M. W. Phillips, J. L. O'Rourke, B. J. Paster, F. E. Dewhirst, G. J. Fraser, J. G. Fox, L. I. Sly, P. J. Romaniuk, T. J. Trust, and S. Kouprach. 1992. Helicobacter muridarum sp. nov., a 
microaerophilic helical bacterium with a novel ultrastructure isolated from the intestinal mucosa of rodents. Int. J. Syst. Bacteriol. 42:27-36.

25. Marshall, B. J., and J. R. Warren. 1984. Unidentified curved bacilli in the stomach of patients with gastritis and peptic ulceration. Lancet i:1311-1314.

26. Nomura, A., G. N. Stemmermann, P. Chyou, I. Kato, G. E. Perez-Perez, and M. J. Blaser. 1991. Helicobacter infection and gastric adenocarcinoma among Japanese Americans in Hawaii. $\mathrm{N}$. Engl. J. Med. 325:1132-1136.

27. Olsen, G. J., R. Overbeek, N. Larsen, T. L. Marsh, M. J. McCaughey, M. A. Maciukenas, W.-M. Kuan, T. J. Macke, Y. Xing, and C. R. Woese. 1992. The ribosomal database project. Nucleic Acids Res. 20:2199-2200.

28. Orlicek, S. L., D. F. Welch, and T. L. Kuhls. 1993. Septicemia and meningitis caused by Helicobacter cinaedi in a neonate. J. Clin. Microbiol. 31:569-571.

29. Parsonnet, J., G. D. Friedman, D. P. Vandersteen, J. H. Chang, J. H. Vogelman, N. Orentriech, and R. K. Sibley. 1991. Helicobacter pylori infection and the risk of gastric adenocarcinoma. $\mathbf{N}$. Engl. J. Med. 325:1127-1131.

30. Paster, B. J., and F. E. Dewhirst. 1988. Phylogeny of campylobacters, wolinellas, Bacteroides gracilis, and Bacteroides ureolyticus by $16 \mathrm{~S}$ ribosomal ribonucleic acid sequencing. Int. J. Syst. Bacteriol. 38:56-62.

31. Paster, B. J., F. E. Dewhirst, C. Seymour, G. J. Fraser, and J. G. Fox. 1991. Helicobacter species isolated from bird and swine feces. Microb. Ecol. Health Dis. 4(Special issue):S107.

32. Paster, B. J., A. Lee, J. G. Fox, F. E. Dewhirst, L. A. Tordoff, G. J. Fraser, J. L. O'Rourke, N. S. Taylor, and R. Ferrero. 1991. Phylogeny of Helicobacter felis sp. nov., Helicobacter mustelae, and related bacteria. Int. J. Syst. Bacteriol. 41:31-38.

33. Reisinger, H. M. 1985. Isolation of thermophilic campylobacters from surface waters: seasonal cycle and correlation with faecal indicators, p. 285-286. In A. D. Pearson, M. B. Skirrow, H. Lior, and B. Rowe (ed.), Campylobacter III. Public Health Laboratory Service, London.

34. Riordan, T., T. J. Humphrey, and A. Fowles. 1993. A point source outbreak of Campylobacter infection related to bird-pecked milk. Epidemiol. Infect. 110:261-265.

35. Saitou, N., and M. Nei. 1987 . The Neighbor-Joining method: a new method for reconstructing phylogenetic trees. Mol. Biol. Evol. 4:406-425.

36. Sambrook, J., E. F. Fritsch, and T. Maniatis. 1989. Molecular cloning: a laboratory manual, 2nd ed., p. 11.31. Cold Spring Harbor Laboratory Press, Cold Spring Harbor, N.Y.
37. Sambrook, J., E. F. Fritsch, and T. Maniatis. 1989. Molecular cloning: a laboratory manual, 2nd ed., p. 11.39. Cold Spring Harbor Laboratory Press, Cold Spring Harbor, N.Y.

38. Schauer, D. B., N. Ghori, and S. Falkow. 1993. Isolation and characterization of "Flexispira rappini" from laboratory mice. J. Clin. Microbiol. 31:2709-2714.

39. Seymour, C., R. G. Lewis, M. Kim, D. F. Gagnon, J. G. Fox, F. E. Dewhirst, and B. J. Paster. 1994. Isolation of Helicobacter strains from wild bird and swine feces. Appl. Environ. Microbiol. 60: $1025-1028$.

40. Sly, L. I., M. A. Bronsdon, J. P. Bowman, A. Holmes, and E. Stackebrandt. 1993. The phylogenetic position of Helicobacter nemestrinae. Int. J. Syst. Bacteriol. 43:386-387.

41. Solnick, J. V., J. O'Rourke, A. Lee, B. J. Paster, F. E. Dewhirst, and L. S. Tomkins. 1993. An uncultured gastric spiral organism is a newly identified Helicobacter in humans. J. Infect. Dis. 168:379385.

42. Stackebrandt, E. 1992. Unifying phylogeny and phenotypic diversity, p. 19-47. In A. Balows, H. G. Trüper, M. Dworkin, W. Harder, and K.-H. Schleifer (ed.), The prokaryotes, 2nd ed. Springer-Verlag, New York.

43. Stanley, J., D. Linton, A. P. Burnens, F. E. Dewhirst, R. J. Owen, A. Porter, S. L. W. On, and M. Costas. 1993. Helicobacter canis sp. nov., a new species from dogs: an integrated study of phenotype and genotype. J. Gen. Microbiol. 139:2495-2504.

44. Stern, N. J. 1992. Reservoirs for Campylobacter jejuni and approaches for intervention in poultry, p. 49-60. In I. Nachamkin, M. J. Blaser, and L. S. Tompkins (ed.), Campylobacter jejunicurrent status and future trends. American Society for Microbiology, Washington, D.C.

45. Studier, J., and K. Keppler. 1988. A note on the Neighbor-Joining algorithm of Saitou and Nei. Mol. Biol. Evol. 5:729-731.

46. Totten, P. A., C. L. Fennell, F. C. Tenover, J. M. Wezenberg, P. L. Perine, W. E. Stamm, and K. K. Holmes. 1985. Campylobacter cinaedi (sp. nov.) and Campylobacter fennelliae (sp. nov.): two new Campylobacter species associated with enteric disease in homosexual men. J. Infect. Dis. 151:131-139.

47. Vandamme, P., E. Falsen, R. Rossau, B. Hoste, P. Segers, R. Tytgat, and J. De Ley. 1991. Revision of Campylobacter, Helicobacter, and Wolinella taxonomy: emendation of generic descriptions and proposal of Arcobacter gen. nov. Int. J. Syst. Bacteriol. 41:88-103.

48. Wesley, I. V., R. D. Wesley, M. Cardella, F. E. Dewhirst, and B. J. Paster. 1991. Oligodeoxynucleotide probes for Campylobacter fetus and Campylobacter hyointestinalis based on 16S rRNA sequences. J. Clin. Microbiol. 29:1812-1817. 